\title{
Sanguibacter soli sp. nov., isolated from soil of a ginseng field
}

\author{
Myung Kyum Kim, ${ }^{1}$ Rama Krishna Pulla, ${ }^{1}$ Se-Young Kim, ${ }^{1}$ Tae-Hoo Yi, ${ }^{1}$ \\ Nak-Kyun Soung ${ }^{2}$ and Deok-Chun Yang ${ }^{1}$
}

Correspondence

Deok-Chun Yang

dcyang@khu.ac.kr

\author{
${ }^{1}$ Korean Ginseng Center and Ginseng Genetic Resource Bank, Kyung Hee University, \\ 1 Seocheon-dong, Kiheung-gu, Yongin, Kyunggi-do 449-701, Republic of Korea \\ ${ }^{2}$ Laboratory of Metabolism, Center for Cancer Research, National Cancer Institute, National \\ Institutes of Health, Bethesda, MD 20892, USA
}

The family Sanguibacteraceae was proposed by Stackebrandt \& Schumann (2000) with Sanguibacter as the type genus. Sanguibacter remains the only described genus within the family. The genus Sanguibacter was proposed by Fernández-Garayzábal et al. (1995) and at the time of writing comprises four recognized species, namely Sanguibacter inulinus (Pascual et al., 1996), Sanguibacter keddieii (Fernández-Garayzábal et al., 1995), Sanguibacter marinus (Huang et al., 2005) and Sanguibacter suarezii (Fernández-Garayzábal et al., 1995).

In a series of studies, we have attempted to isolate microorganisms from soil in order to investigate the community structure based on a culture-dependent method. In the present study, one strain, designated $\mathrm{DCY} 22^{\mathrm{T}}$, was isolated from soil in a ginseng field and was characterized based on a polyphasic approach, including 16S rRNA gene sequence analysis, together with investigations of genomic relatedness and chemotaxonomic and phenotypic properties. The

The GenBank/EMBL/DDBJ accession number for the 16S rRNA gene sequence of strain DCY $22^{\top}$ is EF547937.

A maximum-parsimony tree based on 16S rRNA gene sequences showing the phylogenetic relationships between strain DCY $22^{\top}$ and related species and a table detailing the cellular fatty acid profiles of strain DCY $22^{\top}$ and related species are available as supplementary material with the online version of this paper. results indicate that strain $\mathrm{DCY} 22^{\mathrm{T}}$ represents a novel species of the genus Sanguibacter.

Strain DCY $22^{\mathrm{T}}$ was isolated from surface soil of an agricultural field where ginseng was planted. One gram of the soil was immersed in $50 \mathrm{ml}$ saline solution, vortexed and serially diluted and a $100 \mu \mathrm{l}$ aliquot was inoculated onto one-tenth-strength R2A agar (Difco). The purified colonies were tentatively identified by using analysis of the partial 16S rRNA gene sequence. Cell morphology and motility were observed with a Nikon light microscope ( $\times 1000$ magnification) after incubation on diluted LuriaBertani (LB) agar (0.5\% agar) for 1 day. Gram reactions were conducted according to the non-staining method as described by Buck (1982). Oxidase activity was evaluated via the oxidation of $1 \% p$-aminodimethylaniline oxalate. Catalase activity was determined by measurements of bubble production after the application of $3 \%(\mathrm{v} / \mathrm{v})$ hydrogen peroxide solution. Growth at various temperatures $\left(4,15,25,30,37\right.$ and $\left.42{ }^{\circ} \mathrm{C}\right)$ was assessed on R2A agar, and growth at different $\mathrm{pH}$ values $(\mathrm{pH} 5.0-11.0$ at intervals of $0.5 \mathrm{pH}$ units) was assessed in R2A broth. Growth on nutrient agar, LB agar and trypticase soy agar (TSA) was also evaluated at $30{ }^{\circ} \mathrm{C}$. The API 20NE, API ID32 GN, API 50CH and API ZYM microtest systems were employed in these tests following the recommendations of the manufacturer (bioMérieux). 
Table 1. Differential phenotypic characteristics between strain DCY $22^{\top}$ and type strains of recognized Sanguibacter species

Strains: 1, Sanguibacter soli sp. nov. DCY22 $2^{\mathrm{T}}$; 2, S. marinus 1-19 ${ }^{\mathrm{T}}$ (data from Huang et al., 2005); 3, S. suarezii ST-26 ${ }^{\mathrm{T}}$ (Fernández-Garayzábal et al., 1995); 4, S. inulinus ST-50 ${ }^{\mathrm{T}}$ (Pascual et al., 1996); 5, S. keddieii ST-74 (Fernández-Garayzábal et al., 1995). All are Gram-positive, motile and catalase-positive. All are able to produce acid from L-arabinose, gentiobiose, fructose, galactose, D-glucose, maltose, ribose, arbutin, glycerol, sucrose, D-mannose and D-xylose, but not from melezitose, D-adonitol or D-arabinose. All have MK-9 $\left(\mathrm{H}_{4}\right)$ as the major menaquinone. + , Positive; -, negative; $\mathrm{v}$, variable; $\mathrm{W}$, weakly positive; NA, no data available.

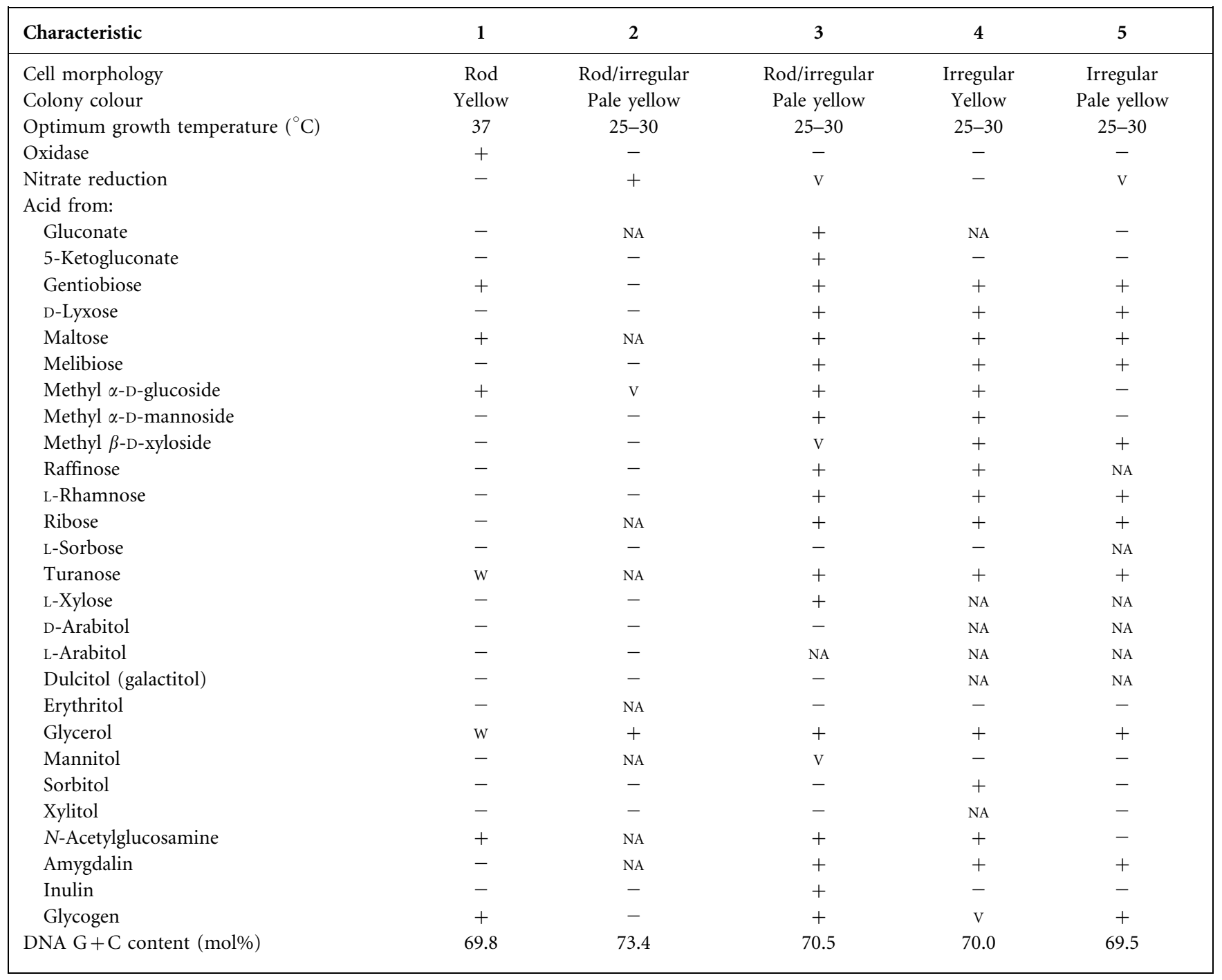

Isoprenoid quinones were extracted with chloroform/ methanol $(2: 1, \mathrm{v} / \mathrm{v})$, purified by TLC and subsequently analysed by HPLC, as described by Collins \& Jones (1981) and Shin et al. (1996). For fatty acid methyl ester analysis, the strain was allowed to grow on TSA for $48 \mathrm{~h}$ at $30^{\circ} \mathrm{C}$, and then two loops of well-grown cells were harvested. Fatty acid methyl esters were prepared, separated and identified by using the Sherlock Microbial Identification System (MIDI, Inc.; Sasser, 1990).

For determination of the $\mathrm{G}+\mathrm{C}$ content, genomic DNA was extracted and purified with the Qiagen Genomic-tip system $100 / G$ and was then enzymically degraded into nucleosides. The nucleosides were analysed by using HPLC as described by Tamaoka \& Komagata (1984) and Mesbah et al. (1989).
The 16S rRNA gene was amplified from chromosomal DNA by using the universal bacterial primer set fD1 and rP1 (Weisburg et al., 1991), and the purified PCR product was sequenced by Genotec (Daejeon, Korea) (Kim et al., 2005). The full $16 \mathrm{~S}$ rRNA gene sequence was compiled with SeqMan software (DNASTAR). The $16 \mathrm{~S}$ rRNA gene sequences of related taxa were obtained from GenBank and edited by using the BioEdit program (Hall, 1999). Multiple alignments were performed with the CLUSTAL_X program (Thompson et al., 1997). Evolutionary distances were calculated according to Kimura's two-parameter model (Kimura, 1983). Phylogenetic trees were constructed via the neighbour-joining method (Saitou \& Nei, 1987) and maximum-parsimony method in the MEGA 2 program (Kumar et al., 2001). Bootstrap analysis with 1000 


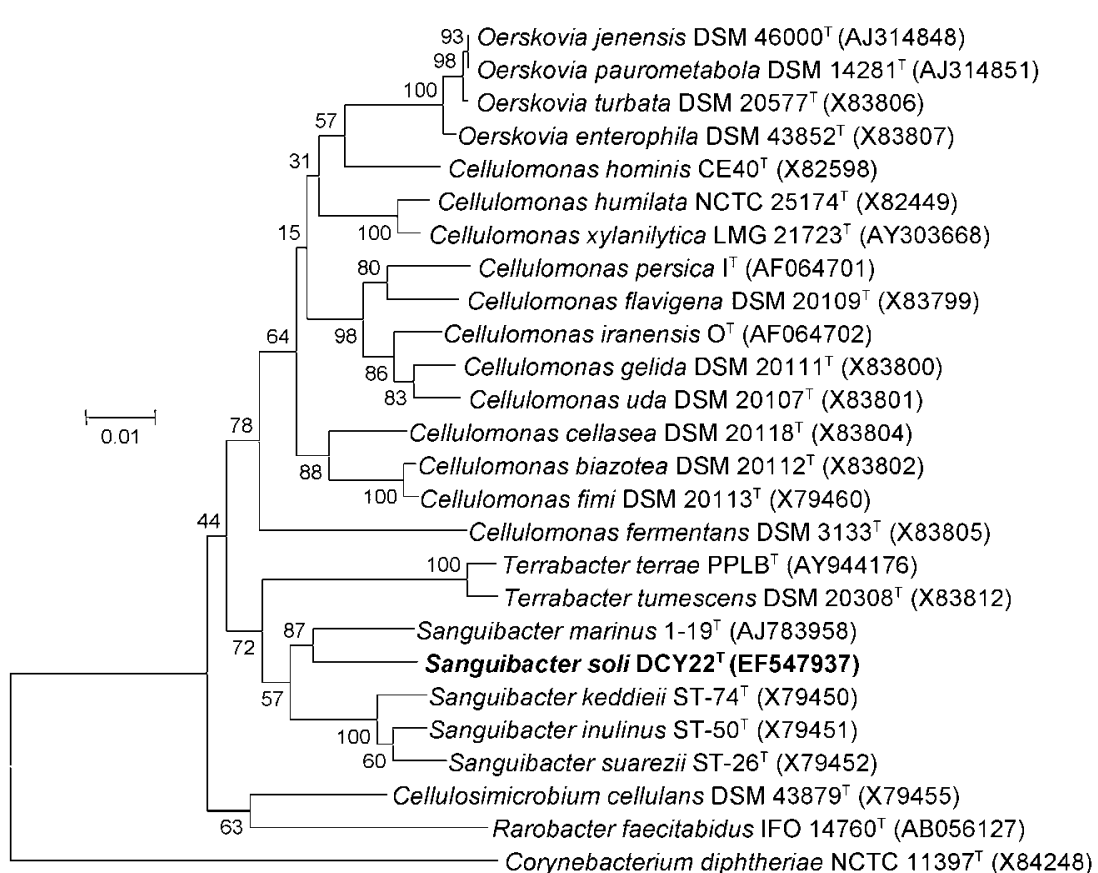

Fig. 1. Neighbour-joining tree based on $16 \mathrm{~S}$ rRNA gene sequences, showing the phylogenetic relationships between strain DCY $22^{\top}$ and related species (all recognized Sanguibacter species and type species of other related genera). Bar, 0.01 substitutions per nucleotide position. replicates was also conducted in order to obtain confidence levels for the branches (Felsenstein, 1985). The closest relatives of strain $\mathrm{DCY} 22^{\mathrm{T}}$, namely the type strains of all recognized Sanguibacter species, and the type species of genera representing all families in the suborder Micrococcineae were included in the phylogenetic tree.

Strain DCY $22^{\mathrm{T}}$ was cultured on R2A agar (Difco) at $30{ }^{\circ} \mathrm{C}$, yielding yellow, circular colonies. Strain $\mathrm{DCY} 22^{\mathrm{T}}$ was found to be an aerobic, Gram-positive, motile, rod-shaped bacterium that was able to grow at $25-42{ }^{\circ} \mathrm{C}$ but not at $4{ }^{\circ} \mathrm{C}$. Growth was observed at $\mathrm{pH} 5-9$. The physiological characteristics of strain $\mathrm{DCY} 22^{\mathrm{T}}$ are summarized in the species description below, and a comparison of differential characteristics with the type strains of recognized Sanguibacter species is given in Table 1 .

The cellular fatty acid profile of strain $\mathrm{DCY} 22^{\mathrm{T}}$ is presented in Supplementary Table S1 (available in IJSEM Online). The major cellular fatty acids found in strain $\mathrm{DCY} 22^{\mathrm{T}}$ were unknown ECL 13.961 (45.81\%), 17:0 anteiso (23.46\%), $18: 0$ iso $(15.42 \%)$, unknown ECL $14.966(8.70 \%), 12: 0$ anteiso $(3.35 \%)$ and $18: 3 \omega 6,9,12 c(2.63 \%)$. Strain DCY $22^{\mathrm{T}}$ lacked 15:0 anteiso and 16:0, both of which are common in recognized species of the genus Sanguibacter and in Terrabacter terrae and Terrabacter tumescens. The fatty acids 17:0 anteiso, 18:0 iso, unknown ECL 13.961 and ECL 14.966 in DCY $22^{\mathrm{T}}$ are not major components of the profiles of recognized Sanguibacter and Terrabacter species.

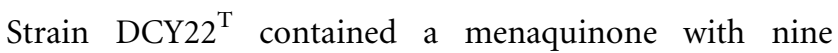
isoprene units (MK-9) as the predominant isoprenoid quinone and a smaller amount of MK-8. MK-9 is commonly found in recognized Sanguibacter species (Pascual et al., 1996; Huang et al., 2005).
The 16S rRNA gene sequence of strain DCY $22^{\mathrm{T}}$ was found to be a continuous stretch of $1395 \mathrm{nt}$. Based on preliminary data, strain $\mathrm{DCY} 22^{\mathrm{T}}$ was determined to belong to the class Actinobacteria, suborder Micrococcineae, family Sanguibacteraceae. Highest levels of $16 \mathrm{~S}$ rRNA gene sequence similarity were found with S. marinus $1-19^{\mathrm{T}}(96.8 \%), S$. suarezii ST-26 ${ }^{\mathrm{T}}(96.0 \%)$, S. inulinus ST-50 ${ }^{\mathrm{T}}(95.9 \%)$, S. keddieii ST- $74^{\mathrm{T}}(95.5 \%)$, T. terrae $\operatorname{PPLB}^{\mathrm{T}}(94.0 \%)$ and $T$. tumescens DSM $20308^{\mathrm{T}}(93.8 \%)$. In the neighbour-joining phylogenetic tree (Fig. 1), strain DCY $22^{\mathrm{T}}$ clearly fell within the Sanguibacter lineage. A maximum-parsimony tree is available as Supplementary Fig. S1.

The G + C content of the genomic DNA of strain DCY $22^{\mathrm{T}}$ was $69.8 \mathrm{~mol} \%$, a value similar to that reported for recognized Sanguibacter species (69.5-73.4 mol\%). On the basis of phenotypic, chemotaxonomic and phylogenetic data, we conclude that strain DCY $22^{\mathrm{T}}$ represents a novel species of the genus Sanguibacter, for which the name Sanguibacter soli sp. nov. is proposed.

\section{Description of Sanguibacter soli sp. nov.}

Sanguibacter soli (so'li. L. neut. gen. n. soli of soil, the source of the type strain).

Cells are Gram-positive, aerobic, motile rods when grown on R2A agar (Difco) at $30{ }^{\circ} \mathrm{C}$ for 5 days. Colonies grown on R2A agar for 5 days are yellow. Optimal growth temperature is $37{ }^{\circ} \mathrm{C}$. Grows at $\mathrm{pH}$ 5-9. Oxidase- and catalase-positive. Acid is produced from L-arabinose, cellobiose, D-fructose, D-galactose, gentiobiose, glycogen, lactose, maltose, D-mannose, methyl $\alpha$-D-glucoside, starch, sucrose, trehalose, turanose, D-xylose, glycerol, $N$-acetylglucosamine, arbutin, aesculin and salicin, but not from 
gluconate, 2-ketogluconate, 5-ketogluconate, D-arabinose, D- or L-fucose, D-lyxose, melezitose, melibiose, methyl $\alpha$-Dmannoside, L-rhamnose, raffinose, ribose, L-sorbose, Dtagatose, L-xylose, D-adonitol (ribitol), D-arabitol, L-arabitol, dulcitol (galactitol), erythritol, inositol, mannitol, sorbitol, xylitol, amygdalin or inulin. Positive for $\mathrm{N}$ acetyl- $\beta$-glucosaminidase, acid phosphatase, alkaline phosphatase, $\alpha$-chymotrypsin, cystine arylamidase, esterase (C4), esterase (C8), $\beta$-galactosidase, $\alpha$-glucosidase, $\beta$ glucosidase (aesculin hydrolysis), $\beta$-glucuronidase, leucine arylamidase, lipase (C14), $\alpha$-mannosidase, naphthol-ASBI-phosphohydrolase, trypsin and valine arylamidase. Negative for arginine dihydrolase, $\alpha$-fucosidase, $\alpha$-galactosidase, protease (gelatin hydrolysis) and urease. Assimilates acetate, L-arabinose, D-glucose, maltose, D-mannose, sucrose, glycogen and salicin, but not 3-hydroxybenzoate, 4hydroxybenzoate, DL-3-hydroxybutyrate, 4-hydroxybenzoate, 2-ketogluconate, 5-ketogluconate, adipate, caprate, citrate, gluconate, itaconate, L-lactate, L-malate, malonate, phenyl acetate, propionate, suberate, n-valerate, L-fucose, melibiose, L-rhamnose, D-ribose, myo-inositol, D-mannitol, D-sorbitol, $N$-acetyl-D-glucosamine, L-alanine, L-histidine, L-proline or L-serine. The DNA G $+\mathrm{C}$ content of the type strain is $69.8 \mathrm{~mol} \%$, as determined by HPLC. The predominant quinone is $\mathrm{MK}-9\left(\mathrm{H}_{4}\right)$. Major cellular fatty acids include unknown ECL 13.961 (45.81\%), 17:0 anteiso $(23.46 \%), 18: 0$ iso $(15.42 \%)$, unknown ECL $14.966(8.70 \%), 12: 0$ anteiso $(3.35 \%)$ and $18: 3 \omega 6,9,12 c$ $(2.63 \%)$.

The type strain, DCY $22^{\mathrm{T}}\left(=\mathrm{KCTC} 13155^{\mathrm{T}}=\mathrm{JCM} 14841^{\mathrm{T}}\right)$, was isolated from soil of a ginseng field in South Korea.

\section{Acknowledgements}

This research was supported by the Kyung Hee University Research Fund in 2004 (KHU-20040204) and by a BK21 research fellowship from the Korean Ministry of Education and Human Resource Development.

\section{References}

Buck, J. D. (1982). Nonstaining (KOH) method for determination of Gram reactions of marine bacteria. Appl Environ Microbiol 44, 992-993.

Collins, M. D. \& Jones, D. (1981). Distribution of isoprenoid quinone structural types in bacteria and their taxonomic implications. Microbiol Rev 45, 316-354.

Felsenstein, J. (1985). Confidence limits on phylogenies: an approach using the bootstrap. Evolution 39, 783-791.

Fernández-Garayzábal, J. F., Dominguez, L., Pascual, C., Jones, D. \& Collins, M. D. (1995). Phenotypic and phylogenetic characterization of some unknown coryneform bacteria isolated from bovine blood and milk: description of Sanguibacter gen. nov. Lett Appl Microbiol 20, 69-75.

Hall, T. A. (1999). BioEdit: a user-friendly biological sequence alignment editor and analysis program for Windows 95/98/NT. Nucleic Acids Symp Ser 41, 95-98.

Huang, Y., Dai, X., He, L., Wang, Y. N., Wang, B. J., Liu, Z. \& Liu, S. J. (2005). Sanguibacter marinus sp. nov., isolated from coastal sediment. Int J Syst Evol Microbiol 55, 1755-1758.

Kim, M. K., Im, W.-T., Ohta, H., Lee, M. \& Lee, S.-T. (2005). Sphingopyxis granuli sp. nov., a $\beta$-glucosidase-producing bacterium in the family Sphingomonadaceae in $\alpha-4$ subclass of the Proteobacteria. J Microbiol 43, 152-157.

Kimura, M. (1983). The Neutral Theory of Molecular Evolution. Cambridge: Cambridge University Press.

Kumar, S., Tamura, K., Jakobsen, I.-B. \& Nei, M. (2001). MEGA2: molecular evolutionary genetics analysis software. Bioinformatics $\mathbf{1 7}$, 1244-1245.

Mesbah, M., Premachandran, U. \& Whitman, W. B. (1989). Precise measurement of the $\mathrm{G}+\mathrm{C}$ content of deoxyribonucleic acid by highperformance liquid chromatography. Int J Syst Bacteriol 39, 159-167.

Montero-Barrientos, M., Rivas, R., Velázquez, E., Monte, E. \& Roig, M. G. (2005). Terrabacter terrae sp. nov., a novel actinomycete isolated from soil in Spain. Int J Syst Evol Microbiol 55, 2491-2495.

Pascual, C., Collins, M. D., Grimont, P. A. D., Dominguez, L. \& Fernández-Garayzábal, J. F. (1996). Sanguibacter inulinus sp. nov. Int J Syst Bacteriol 46, 811-813.

Prauser, H., Schumann, P., Rainey, F. A., Kroppenstedt, R. M. \& Stackebrandt, E. (1997). Terracoccus luteus gen. nov., sp. nov., an LLdiaminopimelic acid-containing coccoid actinomycete from soil. Int $J$ Syst Bacteriol 47, 1218-1224.

Saitou, N. \& Nei, M. (1987). The neighbor-joining method: a new method for reconstructing phylogenetic trees. Mol Biol Evol 4, 406-425.

Sasser, M. (1990). Identification of bacteria by gas chromatography of cellular fatty acids, MIDI Technical Note 101. Newark, DE: MIDI, Inc.

Shin, Y. K., Lee, J.-S., Chun, C. O., Kim, H.-J. \& Park, Y.-H. (1996). Isoprenoid quinone profiles of the Leclercia adecarboxylata KCTC $1036^{\mathrm{T}}$. J Microbiol Biotechnol 6, 68-69.

Stackebrandt, E. \& Schumann, P. (2000). Description of Bogoriellaceae fam. nov., Dermacoccaceae fam. nov., Rarobacteraceae fam. nov. and Sanguibacteraceae fam. nov. and emendation of some families of the suborder Micrococcineae. Int J Syst Evol Microbiol 50, 1279-1285.

Tamaoka, J. \& Komagata, K. (1984). Determination of DNA base composition by reversed-phase high-performance liquid chromatography. FEMS Microbiol Lett 25, 125-128.

Thompson, J. D., Gibson, T. J., Plewniak, F., Jeanmougin, F. \& Higgins, D. G. (1997). The CLUSTAL_X windows interface: flexible strategies for multiple sequence alignment aided by quality analysis tools. Nucleic Acids Res 25, 4876-4882.

Weisburg, W. G., Barns, S. M., Pelletier, D. A. \& Lane, D. J. (1991). 16 S ribosomal DNA amplification for phylogenetic study. J Bacteriol 173, 697-703. 